\title{
Seed longevity of Eragrostis plana Nees buried in natural grassland soil
}

\author{
Renato Borges de Medeiros ${ }^{1}$, Telmo Focht², Leandro Luiz Menegon ${ }^{1}$, Mário Ruschel Freitas ${ }^{1}$ \\ ${ }^{1}$ Departamento de Plantas Forrageiras e Agrometeorologia, Universidade Federal do Rio Grande do Sul, Porto Alegre, RS, Brasil. \\ 2 Departamento de Ecologia, Universidade Federal do Rio Grande do Sul, Porto Alegre, RS, Brasil.
}

\begin{abstract}
The objective of this research was to evaluate the seed longevity of Eragrostis plana Nees buried at different soil depths, in a natural-grassland area in the Pampa biome (46 m altitude, $30^{\circ} 05^{\prime} \mathrm{S}$ and $51^{\circ} 40^{\prime} \mathrm{W}$ ) of Rio Grande do Sul State, Brazil. The experimental design was a split-plot type in complete blocks with two factors: seeds buried at five different depth levels (soil surface and 2.5, 5, 10 and $20 \mathrm{~cm}$ ) and seven exhumation dates. The blocks were allocated in natural grassland grazed by cattle, allocated in a 12-m-long transection. Fifty-four permeable nylon bags filled with 100 seeds in each division, with five vertical divisions, were buried in each row. Seven exhumation dates were used: the first on October 14, 2003 and the last on January 14, 2006. The percentage of viable seeds of E. plana, collected at seven exhumation times and set at different depths in the soil horizon, were described by simple negative exponential equations. Based on the model, the percentage of viable seeds collected at the five depths, (soil surface and 2.5, 5, 10, and $20 \mathrm{~cm}$ ), after 2.5 years of burial, were $0.1,0.5,1.0,7.4$ and $22.1 \%$, respectively. Increase in depth is directly associated with physical and physiological seed integrity of E. plana. Negative simple exponential equations can be used to predict seed longevity of E. plana buried in nylon bags. This invader species accumulates soil seed-bank of high longevity.
\end{abstract}

Key Words: biological invasion, invader species, Pampa biome, recovered seeds, seed bank, surviving seeds

\section{Introduction}

Native pasture is the main diet of sheep and cattle in Rio Grande do Sul State, Brazil. In spite of its economic and environmental importance, this natural resource is losing its quality as forage due to the continuous invasion and expansion of Eragrostis plana. This invasion has determined drastic reduction in frequency and abundance of native species and losses in the animal productivity (Medeiros et al., 2009). The area occupied by E. plana is estimated to be larger than one million hectares (Medeiros and Focht, 2007).

Its expansion results from the ingestive behavior of animals under continuous grazing, in which, in the best growing pasture period (spring), they prefer to ingest the native prostrate species with higher nutritional value rather than the E. plana tussock (Medeiros et al., 2009). In selective grazing, E. plana grows in low competition, producing intense flow of panicles from November to March. When the native forage quality starts to diminish,

Received November 26, 2013 and accepted September 14, 2014. Corresponding author: tefocht@gmail.com

http://dx.doi.org/10.1590/S1516-35982014001100001

Copyright (C) 2014 Sociedade Brasileira de Zootecnia. This is an Open Access article distributed under the terms of the Creative Commons Attribution Non-Commercial License, which permits unrestricted non-commercial use, distribution, and reproduction in any medium, provided the original work is properly cited. in summer, the animals attempt to compensate their diet by ingesting the invader, preferring the panicles, the most palatable part of the adult plant (Medeiros et al., 2009). One fraction of the seeds produced in the panicles accumulates in the soil seed bank. Another seed fraction is ingested by the animals and distributed locally by the feces or, in the case of animal transport, invades areas in other regions through the preserved seeds, which are viable for up to three days in the feces after ingestion (Medeiros et al., 2009).

There is a lack of a long-term research on E. plana upon soil seed bank (SSB) dynamics, basic factor of its invasion process and persistence. The seed size is an important indicator of SSB dynamics. Small grass seeds are compact and do not have awns, and, as a consequence, they avoid germination, predation or secondary dispersion. In view of that, they get deeper in the soil and remain viable for many years (Milberg, 1992; Baskin and Baskin, 2001). Seeds of E. plana, with an average weight of $0.21 \mathrm{~g}$ of a thousand seeds, fit in this seed group (Medeiros and Focht, 2007). These attributes qualify the seeds to build up a persistent type of SSB, which allows the seed to last longer than a year and to germinate in many fluxes through years (Medeiros et al., 2009).

The objective of this study was to determine the longevity of seeds of E. plana buried in nylon bags, in a natural-grassland, under grazing on a Plintossoil, located in the Pampa biome of RS State, Brazil. 


\section{Material and Methods}

This study was carried out at Estação Experimental Agronômica (Universidade Federal do Rio Grande do Sul), located at $46 \mathrm{~m}$ altitude, $30^{\circ} 05^{\prime} \mathrm{S}$ and $51^{\circ} 40^{\prime} \mathrm{W}$. According to Köppen, the climatic classification of the region is a subtropical humid Cfa type (Trewartha and Horn, 1980), with average temperatures between $14{ }^{\circ} \mathrm{C}$ (coldest months) and $24{ }^{\circ} \mathrm{C}$ (warmest months), maximum and minimum temperatures between $37.3^{\circ} \mathrm{C}$ and $-0.9^{\circ} \mathrm{C}$, respectively, and frosts can occur from April to October (Moreno, 1961). The annual average rainfall is $1,398 \mathrm{~mm}$, with more frequent dry spells from November to March. The soil in the studied area is a Plintossoil Argiluvic Eutrofic Abrupt (Mendonça, 2006), corresponding to Plintossoil (FAO, 2008), a Durasnal mapping unit (Streck et al., 2002).

The tested seeds were harvested between December 2002 and March 2003, at Estância Upacaraí, in the municipality of Dom Pedrito/RS, Brazil. The seed was harvested manually, cutting the entire panicle. The seeds were placed inside a cotton bag, suspended in the air in a shed, which dried slowly to ensure high physiologic quality.

The experimental design was a split-plot type in complete blocks. The treatments were: 1) soil depth: soil surface and $2.5,5,10$, and $20 \mathrm{~cm} ; 2$ ) seven dates of exhumation. The first four exhumation dates were spaced in intervals of three months, and the last three were spaced in six-month intervals. Fifty-four permeable nylon bags were buried. The seeds were placed in the soil profile inside nylon bags (Van Mourik et al., 2005), and buried along the transect line, $20 \mathrm{~cm}$ distant from each other. The nylon bags, with five vertical divisions, containing 100 seeds in each division, were buried in three steps: 1) V-shaped hole cut vertically using a shovel in a friable soil; 2) the bags were inserted in the V-shaped hole using a wood ruler; 3) V-shaped hole was closed with the shovel. The bags were buried in the soil on July 14, 2003. The first exhumation was carried out on October 14, 2003 and the last one on January 14, 2006, corresponding to 914 days of burial. From this time on, the seed longevity was calculated utilizing simple exponential equations until exhaustion of all buried seeds. The nylon bags were allocated in a 12-m-long transect, parallel to a wire fence in a natural grassland area under cattle continuous grazing. The transect was set $1 \mathrm{~m}$ distant from the grazing zone, in order to avoid the impact of animal hoofs close to the wire fence. The grazing effect was imposed by removing the forage mass, in an attempt to keep the pasture height similar to the adjoining grazing area.

Six nylon bags were exhumed from the first to the fourth day. However, the standard deviation of viable seeds
(STDEV) of all buried depths increased from the first to the fourth exhumation, presenting values of $7.3 \%$ and $21.2 \%$, respectively. Due to the high variation in standard deviation, especially for the seeds placed in a further depth, it was necessary to increase the number of nylon bags in order to keep the standard deviation around acceptable values. Because of that, 8,10 and 12 nylon bags were taken in the fifth, sixth and seventh exhumations, respectively.

The exhumed seeds with tegument and endosperm, found inside the nylon bag, were counted and subjected to germination tests. Four seed fractions were separated: 1) exhumed (apparently alive); 2) viable (germinated using cold test); 3) viable by tetrazolium tests (TZ) (with embryo dormancy); 4) and total viable (germinated + tetrazolium seed test) seeds. The seed germination tests were performed utilizing gearbox and germitest paper. As the seeds of E. plana presented embryo dormancy, it was necessary to apply the cold test using a solution of $\mathrm{KNO}_{3}$ at $0.2 \%$, combined with low temperature treatment of $5{ }^{\circ} \mathrm{C}$ for seven days. The germination chambers were adjusted to a temperature of $20^{\circ} \mathrm{C}$ in dark periods of $8 \mathrm{~h}$ and $30^{\circ} \mathrm{C}$ in day periods of $16 \mathrm{~h}$. The seedlings registered in the gearbox were counted daily for 27 days and they were considered germinated when the radicles presented $3 \mathrm{~mm}$ in length. The seeds that did not germinate in the germination test + cold test and stayed firm, apparently alive, were subjected to tetrazolium test according to the Seed Analysis Rules (Brasil, 2009).

The records of the viable and dormant seeds (total viable seeds) exhumed were subjected to the calculations of the standard deviation (STDEV), using the SAS (Statistical Analysis System, version 6.08) program. The SAS was also used to calculate the linear and polynomial equations and the coefficients of determination, and simple negative exponential equations were used to estimate the surviving seeds buried in the soil (Murdock and Ellis, 2000).

\section{Results and Discussion}

The average number of recorded seeds, in terms of all burial depths in the first, second and third exhumations were 95.1, 90.6 and 93.0, respectively (Table 1). It was shown that 9 months time caused an average disappearance of only $7.1 \%$ of E. plana buried seeds. The effect of seed burial, in this period, showed that the exhumed seeds preserved their physical integrity. In this period, the average values of the exhumed seeds, due to the buried depths, were similar. In the fourth exhumation, one year after the seeds of E. plana were buried, a high rate of disappearance was recorded, and the average exhumed seeds dropped to 74.9. However, the 
exhumation of the seeds placed on the soil surface dropped to $61.3 \%$, while those exhumed at $20 \mathrm{~cm}$ depth presented $90.7 \%$, which resulted in $29.4 \%$ of amplitude between them. The seeds exhumed from greater depths, after one year of burial, still preserved their physical integrity. These results indicate that after one year of burial the seeds placed on soil surface and at $2.5 \mathrm{~cm}$ depth showed a higher rate of disappearance in comparison with the seeds placed at greater depths, especially those located at 10 and $20 \mathrm{~cm}$ depth. From this date on, the exhumed E. plana seed disappearance rates followed the same pattern until the last exhumation, performed 2.5 years after the beginning of the experiment.

The highest average percentage of germinated seeds of E. plana, in terms of five burial depths, was $72.5 \%$ in the first exhumation (Table 1). However, in the second exhumation,

Table 1 - Average percentage of exhumed, germinated $(\mathrm{G})$, viable seeds by the tetrazolium test $(\mathrm{TZ})$ and total viable seeds $(\mathrm{TV}=\mathrm{G}+\mathrm{TZ})$ and standard deviation of the viable seeds (STDEV) of E. plana buried at five depths, on seven exhumation dates

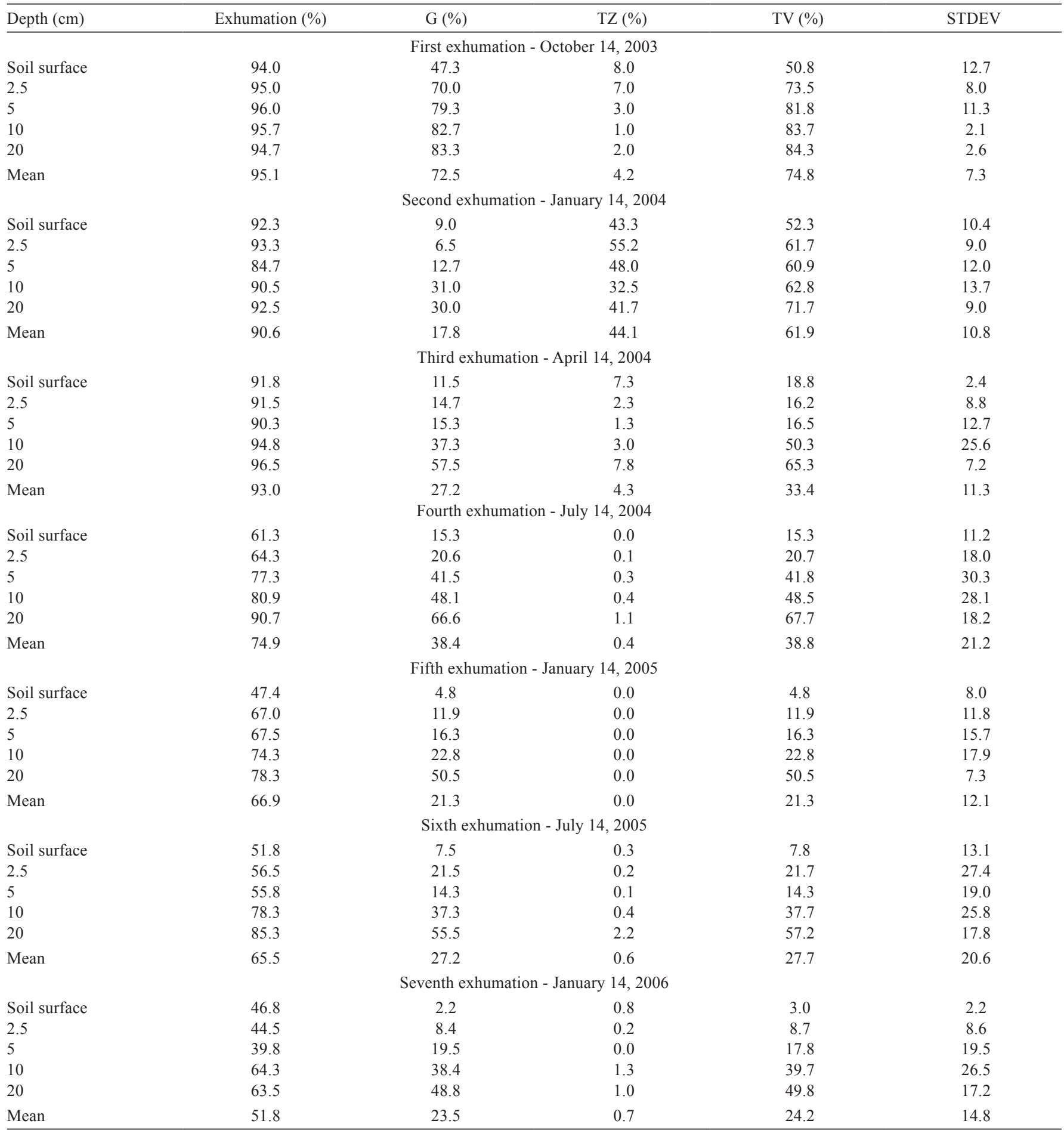


a severe drop in the average rate of seed germination was recorded. This means that a few seeds had their dormancy removed by cold test (Brasil, 2009), especially the seeds placed at the upper soil layers. This reduction in the rate of seed germination can be explained, in part, by a deep induction of the secondary dormancy, as discussed in the literature (Bewley and Black, 1994). Thus, the high percentage of seed viability obtained in the tetrazolium test can explain the low percentage of seed germination. From the third exhumation on, the percentage of the average seed germination of E. plana decreased in comparison with the second one. From the fourth exhumation on, one year after seed burial of E. plana, the germination percentage starts to diminish gradually. From this period on, as dates of exhumation proceed, seeds placed deeper in soil are better preserved and have higher germination percentage in comparison with those placed on the soil surface.

The tetrazolium test (TZ) was adopted to check if the exhumed seeds of E. plana showed viability after the germination tests (Table 1). In the first three exhumations, the TZ results showed that some seeds did not germinate, even though they were subjected to a treatment of dormancy removal, using the cold test $\left(5^{\circ} \mathrm{C}\right)$ for seven days (Brasil, 2009). It is possible that these seeds present deep physiological embryo dormancy, especially the seeds of the second exhumation, when the majority did not germinate, even though they were viable. Additionally, a few seeds still did not germinate because they were in a process of deterioration, or dead. But an expressive number of viable seeds from the second exhumation acquired secondary dormancy, as discussed by Bewley and Black (1994) and Baskin and Baskin (2001). On the contrary, after the third exhumation, a very low number of viable seeds of $E$. plana was recorded in the TZ test and, as a consequence, these values presented very low practical importance. It is recognized that the seeds of E. plana have embryo dormancy. According to the literature, $50 \%$ of the seeds are dormant just after ripeness (Medeiros et al., 2009). Based on this data, it can be assumed that about $50 \%$ of the seeds of E. plana were dormant when they were buried and they lost dormancy a few months later. Therefore, it can be inferred that the viable seeds of E. plana of the second exhumation buried in the soil, acquired the secondary dormancy, and lost it again after some time.

The STDEV of viable seeds of E. plana in the first four exhumations and in all buried depths increased from the first to the fourth exhumation, presenting values of $7.3 \%$ and $21.2 \%$, respectively (Table 1 ). Six nylon bags were taken in these exhumations. Due to a high variation in the standard deviation, especially in the seeds placed in further depths, it was necessary to increase the number of nylon bags in order to keep the standard deviation around acceptable values. Thus, 8, 10 and 12 nylon bags of buried bags were tested in the last three exhumations, and the results indicated that the increased number of nylon bags, more or less, stabilized the STDEV. Even so, the standard deviations with 10 and 12 nylon bags still had some high deviations, such as $27.4 \%, 26.5 \%$, and $25.8 \%$, respectively (Table 1). These attempts indicate that it was prudent to increase the number of nylon bags in order to control the value of the STDEV. Part of the higher deviations can occur due to activity of fungi (Kremer, 1993; Van Mourik et al., 2005) and other microorganisms of the soil habitat (Baskin and Baskin, 2001). Nonpersistent seeds are lost from the seed bank through mortality because of aging, attacks by seed predators, seed decay and fatal germination (Baskin and Baskin, 2001).

The first and the seventh functions were expressed by the second-grade polynomial regression and the others were expressed by positive linear regression (Figure 1). The adjustment of the linear regressions was coherent and showed similar coefficients of determination, varying from $r^{2}=0.84$ to $r^{2}=0.98$. The first and seventh polynomial equations show similar coefficients of determination, varying from $r^{2}=0.86$ to $r^{2}=0.98$. According to the last polynomial equation (last exhumation - 914 days of burial), the number of viable seeds on the soil surface dropped to $3.0 \%$, while those placed in deeper soil depths still have $49.8 \%$ of seeds alive. Despite the seven equations, linear or polynomial, there are pattern responses in which the seed viability of E. plana is always lower when the seeds are placed at topsoil depths (soil surface and $2.5 \mathrm{~cm}$ ). On the contrary, those placed at deeper soil depths $(10$ and $20 \mathrm{~cm})$ tend to live longer. The negative exponential equation of the average percentage of viable seeds, of five burial depths in the seven exhumations, is expressed in days of evaluation (Figure 1h).

Considering the average percentage of burial depths of seeds viability of $74.8 \%$ in the first evaluation (91 days), the seed viability dropped to $21.3 \%$ after 1.5 years (Table 2 ). In the last two exhumations it dropped to $27.7 \%$, and $23.8 \%$ after 2.0 and 2.5 years. This means that, regardless of the burial depth, the average seed viability of E. plana decreased by $53.3 \%$ in approximately 1.5 years. The average percentage of seed viability in relation to burial depth, in the first exhumation, 91 days later, showed that the highest percentage was $84.3 \%$, for the seeds placed at a depth of $20 \mathrm{~cm}$. The lowest percentage of viable seed of E. plana was $3.0 \%$ in the last exhumation, 2.5 years after burial. 

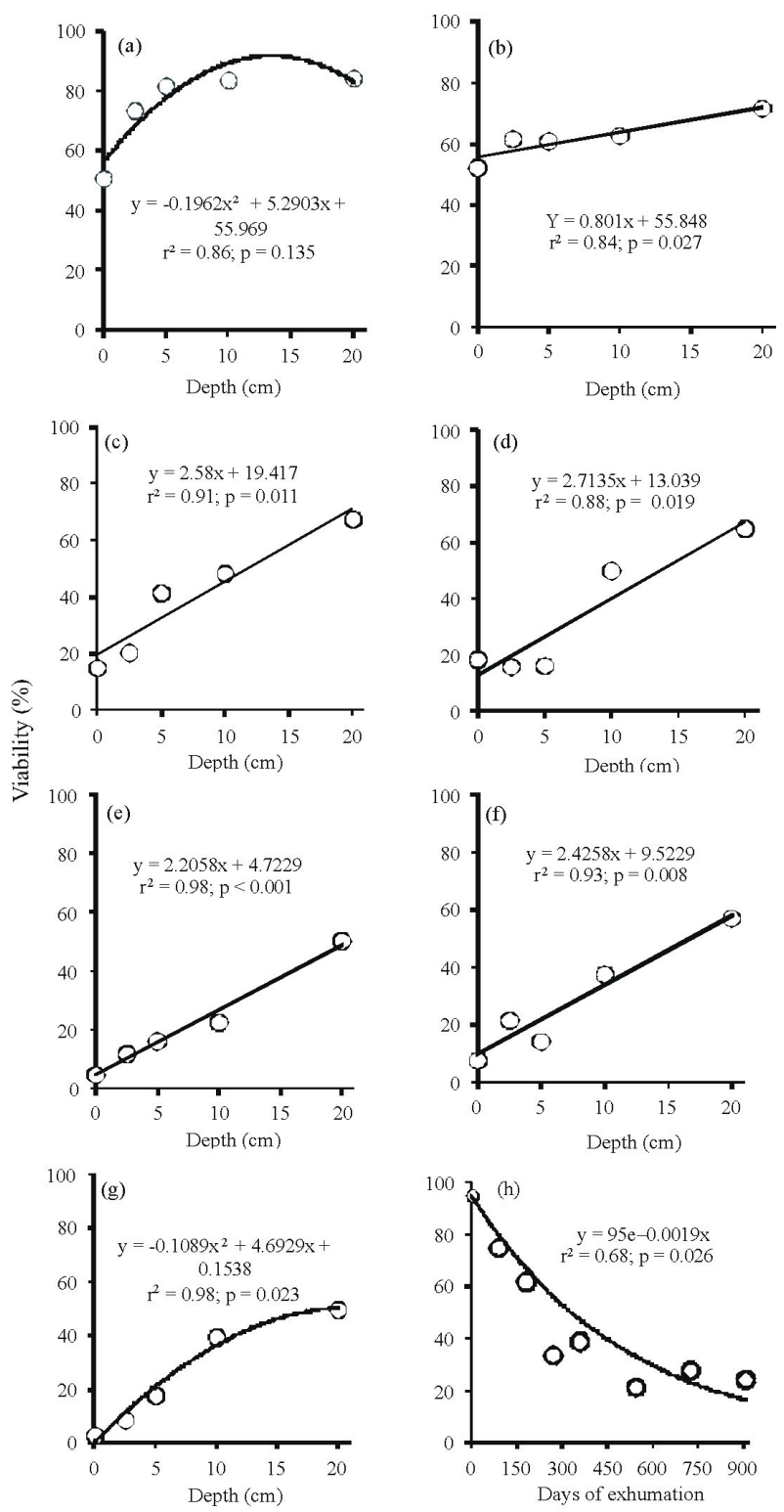

Each dot represents means of: equations (a); (b); (c) and (d) six observations; equation (e) eight; equation (f) ten; (g) twelve; equation (h) derived from exhumation seven.

Figure 1 - Quadratic polynomial equations (a and g) and linear equations (b, c, d, e and $\mathrm{f}$ ) expressed between the average percentage of seed viability and burial depth, and the negative exponential equation $(h)$ expressed between the average seed viability, as an average of all burial depths, in terms of exhumation days of E. plana.
The objective of this research was to continue the exhumations until the complete exhaustion of E. plana seeds buried in nylon bags at all burial depths. As previously mentioned, the permanent increase in the average standard deviations of the seeds inside the nylon bags, up to the fourth exhumation, however, imposed the necessity of exhuming a higher number of nylon bags. Due to the limited number of nylon bags initially buried (54), it was chosen to predict the viable seeds using the registered data presented in Table 2. The results obtained by equations showed that the recovery of the viable seeds through time, in terms of five depths, were described by a negative exponential model (Figure 2 and Table 3 ). The coefficients of determination of the exponential equations, in terms of burial depths of soil surface and $2.5,5,10$ and $20 \mathrm{~cm}$ were $\mathrm{r}^{2}=0.95 ; \mathrm{r}^{2}=0.81$; $r^{2}=0.77 ; r^{2}=0.73 ;$ and $r^{2}=0.70$, respectively. This means that as the seed burial depths increase, the values of the coefficients of determination decrease. This fact indicates that the prediction of seed longevity, using the exponential equations, decreased as the burial depths increased. Therefore, the longevity of seeds placed at the upper soil levels is better estimated than that of seeds planted deeper $(20 \mathrm{~cm})$.

The coefficients of determination between the recovered viable seeds of E. plana in the nylon bags in the seven exhumations versus the predicted viable seeds obtained by the equation model were: $r^{2}=0.85 ; r^{2}=0.92 ; r^{2}=0.94$; $r^{2}=0.96 ; r^{2}=0.96 ; r^{2}=0.98 ;$ and $r^{2}=0.97$ (Figure 2 ). In view of high correlations, the simple negative exponential equations can be utilized to model the surviving seeds buried in the different layers of the soil (Murdock and Ellis, 2000). In this case, the model indicated a high rate of seed disappearance in the first year, especially the seeds placed on soil surface. Thereafter, a deceleration occurred with lower rate of disappearance. The model showed that the germination viability of the seeds placed at deeper soil depths was less impaired by their time of permanence in the soil than of those located on topsoil. According to the model, the seeds placed at soil surface survived around three years,

Table 2 - Average viability of seeds of E. plana in terms of burial depth and days of exhumation in nylon bags placed in the soil

\begin{tabular}{|c|c|c|c|c|c|c|c|}
\hline \multirow[b]{2}{*}{ Depth (cm) } & \multicolumn{7}{|c|}{ Days of exhumation } \\
\hline & 91 & 181 & 270 & 361 & 545 & 725 & 909 \\
\hline & & & & $(\%)$ & & & \\
\hline Soil surface & 50.8 & 52.3 & 18.8 & 15.3 & 4.8 & 7.8 & 3.0 \\
\hline 2.5 & 73.5 & 61.7 & 16.2 & 20.7 & 11.9 & 21.7 & 8.7 \\
\hline 5 & 81.8 & 60.9 & 16.5 & 41.8 & 16.3 & 14.3 & 19.5 \\
\hline 10 & 83.7 & 62.8 & 50.3 & 48.5 & 22.8 & 37.7 & 39.7 \\
\hline 20 & 84.3 & 71.7 & 65.3 & 67.7 & 50.5 & 57.2 & 49.8 \\
\hline Mean & 74.8 & 61.9 & 33.4 & 38.8 & 21.3 & 27.7 & 25.2 \\
\hline
\end{tabular}


while the seeds placed at $20 \mathrm{~cm}$ depth can stay alive for more than twenty years. These results confirm that E. plana forms soil seed-bank of high longevity. Viable seeds have been found in the soil up to 36 years (Milberg, 1992; Baskin and Baskin 2001). In Swedish grassland, eight species that had not been observed in the extant vegetation for 35 years were found in the soil seed bank (Milberg, 1992)

According to Baskin and Baskin (2001), it is assumed that seeds placed at higher depths are older than seeds placed on topsoil. Seed size and shape are important indicators of the soil seed-bank dynamics (Bekker et al., 1998). Big seeds with awns have high surface/volume ratios and have lower probability to be incorporated in the soil seed bank. On the contrary, compacted small grass seeds can be incorporated into the soil and escape processes that prevent penetration into the soil, germination, predation and secondary dispersion, and they tend to stay alive longer in seed banks (Baskin and Baskin, 2001; Medeiros et al., 2009). Seeds of E. plana with $1 \mathrm{~mm}$ in length, $0.5 \mathrm{~mm}$ in width, and thousand seed weight of $0.21 \mathrm{~g}$ fit in this group (Baskin and Baskin, 2001; Medeiros et al., 2009).

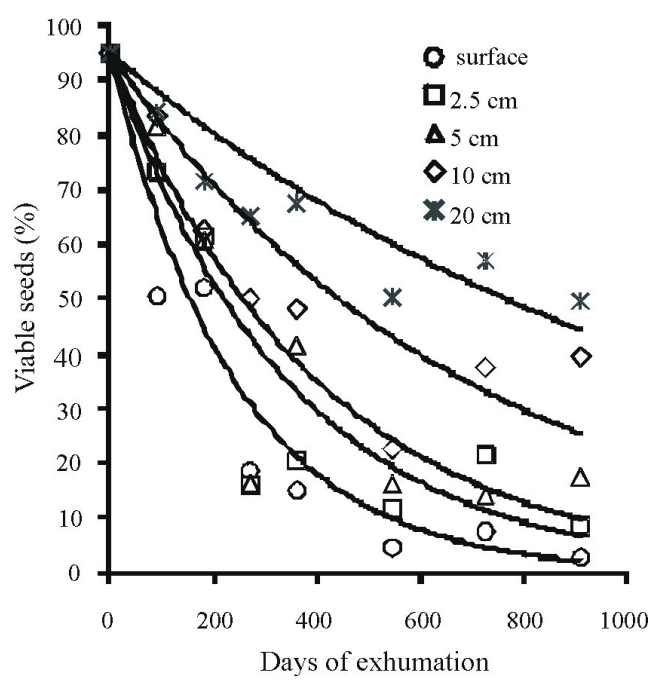

Figure 2 - Exponential equations from data of the percentage of viable seeds of E. plana in terms of interaction of burial depths and days of exhumation.
Van Mourik et al. (2005) observed that high seed densities placed in bulk in nylon bags lost viability rapidly due to the attack of soil fungi. In accordance with that author, at densities around 1,000 seeds per nylon bag, the mortality rate is extremely high. In the present study, using the same permeable nylon bags recommended by Van Mourik et al. (2005) with seeds placed in five different vertical positions, instead of bulk, the attack of fungi was supposed to be reduced. However, the idea of removing the forage mass, in an attempt to keep the pasture height similar to the adjoining grazing area, was not completely achieved. During the exhumations, it was observed that the seeds in the nylon bags, placed on the soil surface, were gradually covered by the accumulation of dead material and soil. Thus, the way the nylon bags were placed in the soil surface might have favored the seed longevity, leading the models that overestimate the seed survival of E. plana on topsoil.

This study showed that as long as the exhumations continued, the seed disappearance rate of E. plana, placed on the surface soil layer was higher than that located at deeper soil depths. According to Benvenuti et al. (2001), emergence from the weed seed-bank declines as a function of increasing seed burial depth, primarily because of depth inhibition by dormancy, although fatal germination also accounts for part of the declination in seedling emergence. Mohler (2001) and Davis and Renner (2007) observed that seeds located near the soil surface are more susceptible to germinate due to environmental variations (light, temperature, moisture, etc.). But, in the case of the existence of allelopathic effects, the seed germination rate would decrease (Liebman and Mohler, 2001).

This study found that seeds of E. plana survive on soil surface around three years, and those buried at a depth of $20 \mathrm{~cm}$ may stay alive for approximately 20 years. As a consequence, the seed bank is qualified to invade in circumstances of soil disturbance. This means that the process of invasion can take place any time when the supply of resources is higher than the resources demanded by the plant community (Davis et al., 2000; Davis, 2009).

Table 3 - Prediction of the percentage of viable seeds of E. plana calculated based on negative exponential model of Figure 2, in terms of burial depth and exhumation years

\begin{tabular}{|c|c|c|c|c|c|c|c|c|c|c|}
\hline \multirow[b]{2}{*}{ Depth (cm) } & \multirow[b]{2}{*}{ Exponential model } & \multicolumn{9}{|c|}{ Years after burial } \\
\hline & & $r^{2}$ & 1 & 2 & 3 & 4 & 5 & 10 & 20 & 25 \\
\hline & & \multicolumn{9}{|c|}{ Viable seeds } \\
\hline Soil surface & $\mathrm{Y}=95 \mathrm{e}^{-0.0041 \mathrm{x}}$ & 0.95 & 21.3 & 4.8 & 1.1 & 0.2 & 0.1 & 0.0 & 0.0 & 0.0 \\
\hline 2.5 & $\mathrm{Y}=95 \mathrm{e}^{-0.0029 \mathrm{x}}$ & 0.81 & 33.0 & 11.4 & 4.0 & 1.4 & 0.5 & 0.0 & 0.0 & 0.0 \\
\hline 5 & $\mathrm{Y}=95 \mathrm{e}^{-0.0025 \mathrm{x}}$ & 0.77 & 38.1 & 15.3 & 6.1 & 2.15 & 1.0 & 0.0 & 0.0 & 0.0 \\
\hline 10 & $Y=95 e^{-0.0014 x}$ & 0.73 & 57.0 & 34.2 & 20.5 & 12.3 & 7.4 & 0.6 & 0.0 & 0.0 \\
\hline 20 & $Y=95 e^{-0.008 x}$ & 0.70 & 70.9 & 53.0 & 38.6 & 29.5 & 22.1 & 4.9 & 0.3 & 0.1 \\
\hline
\end{tabular}




\section{Conclusions}

Seeds of Eragrostis plana placed deep in the soil show higher preservation of physical integrity than those located near topsoil. Seeds placed on topsoil show a higher disappearance rate as compard with seeds buried at greater depths. Superficial seeds can be alive up for to three years, while those planted at higher depths can survive more than twenty years. Eragrostis plana forms soil seed-bank of high longevity and it is recommended to use the direct drill system as an agronomic practice in cropping areas. It is important to stimulate the producers to avoid the use of any management practices that require soil disturbance in areas that have accumulated superficial or deep soil seed-bank of E. plana.

\section{References}

Baskin, C. C. and Baskin, J. M. 2001. Seeds, ecology, biogeography and evolution of dormancy, and germination. Academic Press, San Diego.

Bekker, R. M.; Bakker, J. P.; Grandin, U.; Kalamees, R.; Milberg, P.; Poschlod, P.; Thompson, K. and Willems, J. H. 1998. Seed size, shape and vertical distribution in the soil: indicators of seed longevity. Functional Ecology 12:834-842.

Benvenuti, S.; Macchia, M. and Miele, S. 2001. Quantitative analysis of emergence of seedlings from buried weed seeds with increasing soil depth. Weed Science 49:528-535.

Bewley, J. D. and Black, M. 1994. Seeds: Physiology of development and germination. 2nd ed. Plenum Press, New York.

Brasil. Ministério da Agricultura, Pecuária e Abastecimento. Secretaria de Defesa Agropecuária. 2009. Regras para análise de sementes. Mapa/ACS, Brasília.

Davis, M. A. 2009. Invasion biology. Oxford University Press, New York.

Davis, M. A.; Grime, J. P. and Thompson, K. 2000. Fluctuating resources in plant communities: a general theory of invasibilty. Journal of Ecology 88:528-534.
Davis, A. S. and Renner, K. A. 2007. Influence of seed depth and pathogens on fatal germination of velvetleaf (Abutilon theophrasti) and giant foxtail (Setaria faberi). Weed Science 55:30-35.

FAO/IIASA/ISRIC/ISSCAS and JRC. 2008. Harmonized world soil database (version 1.2). FAO, Rome, Italy and IIASA, Luxemburg, Austria.

Kremer, J. R. 1993. Management of weed seed banks with microorganims. Ecological Applications 3:42-52.

Liebman, M. and Mohler, C. L. 2001. Weeds and the soil environment. p.210-268. In: Ecological management of agricultural weeds. Liebman, M.; Mohler, C. L. and Staver, C. P., eds. Cambridge University Press, Cambridge.

Medeiros, R. B. and Focht, T. 2007. Invasão, prevenção, controle e utilização do capim-annoni-2 (Eragrostis plana Nees) no Rio Grande do Sul. Pesquisa Agropecuária Gaúcha 13:105-114.

Medeiros, R. B.; Saibro, J. C. and Focht, T. 2009. Invasão do capimannoni (Eragrostis plana Nees) no bioma Pampa do Rio Grande do Sul. p.317-330. In: Campos Sulinos - conservação e uso sustentável da biodiversidade. Pillar, V. D. P.; Müller, S. C.; Castilhos, Z. M. and Jacques, A. V. A., eds. Ministério do Meio Ambiente, Brasília.

Mendonça, J. F. B. 2006. Solo: substrato da vida. Embrapa Recursos Genéticos e Biotecnologia, Brasília

Milberg, P. 1992. Seed bank in a 35-year-old experiment with different treatments of a semi-natural grassland. Acta Oecologica 13:793-752.

Mohler, C. L. 2001. Weed evolution and community structure. p.444-493. In: Ecological management of agricultural weeds. Liebman, M.; Mohler, C. L. and Staver, C. P., eds. Cambridge University Press, Cambridge.

Moreno, J. A. 1961. Clima do Rio Grande do Sul. Secretaria de Agricultura, Porto Alegre.

Murdock, A. J. and Ellis, R. H. 2000. Dormancy, viability and longevity. p.193-229. In: Seeds: The ecology of regeneration in plant communities. Fenner, M., ed. CAB International, Wallingford.

Streck, E. V.; Kämpf, N.; Dalmolin, R. S. D.; Klamt, E.; Nascimento, P. C. and Scheider, P. 2002. Solos do Rio Grande do Sul. EMATER/RS e UFRGS, Porto Alegre.

Trewartha, G. T. and Horn, L. H. 1980. Köppen's classification of climates. p.397-403. In: An introduction to climate. McGraw-Hill, New York.

Van Mourik, T. A.; Stomph, T. J. and Murdoch, A. J. 2005. Why high seed densities within burial mesh bags may overestimate depletion rates of soil seed-banks. Journal of Applied Ecology 42:299-305. 